\title{
CORRECTION
}

\section{Correction: SpeCond: a method to detect condition-specific gene expression}

Florence MG Cavalli*1, Richard Bourgon 1,3, Juan M Vaquerizas ${ }^{1}$ and Nicholas M Luscombe ${ }^{1,2}$

\section{Correction}

A corrected author list has been published for the article in which SpeCond is described [1]. Wolfgang Huber has been removed at his and the authors' request. The author list of this correction article reflects this change.

\section{Author details}

'EMBL-European Bioinformatics Institute, Wellcome Trust Genome Campus, Cambridge CB10 1SD, UK. 'EMBL-Heidelberg Genome Biology Unit,

Meyerhofstraße 1, 69117 Heidelberg, Germany. ${ }^{3}$ current address: Department of Bioinformatics, Genentech Inc., 1 DNA Way, South San Francisco, California 94080, USA.
Published: 30 December 2011

\section{References}

1. Cavalli FMG, Bourgon R, Huber W, Vaquerizas JM, Luscombe NM: SpeCond: a method to detect condition-specific gene expression. Genome Biology 2011, 12:R101

doi:10.1186/gb-2011-12-12-413

Cite this article as: Cavalli FMG, et al:: Correction: SpeCond: a method to detect condition-specific gene expression. Genome Biology 2011, 12:413.

Full list of author information is available at the end of the article 